\title{
The Benefits of early Extubation in OR and ICU after Cardiac Surgery
}

\author{
Saimir Kuci ${ }^{1 *}$, Alfred Ibrahimi ${ }^{1}$, Ermal Likaj ${ }^{1}$, Stavri Llazo $^{1}$, Ervin Bejko ${ }^{1}$, \\ Marsela Goga ${ }^{1}$, Selman Dumani ${ }^{2}$, Ali Refatllari ${ }^{2}$, Jacob Zeitani ${ }^{1}$
}

Received: 12 July 2020 / Accepted: 3 August 2020 / Published online: 20 January 2021

(C) The Author(s) 2021. This article is published with open access at https://journal.astes.org.al

\begin{abstract}
Objective: Operating room (OR) extubation after adult cardiac surgery with cardiopulmonary bypass CPB is rare. We examined the outcome, factors and benefits of OR extubation.

Methods: We operated 60 patients in German Hospital Tirana, from January 2019 to September 2020, who had undergone CABG cardiac operations: 52 patients, mitral valve repair 5 patients, aortic stenosis 1patient, Bentall procedure 1 patient, left atrial myxoma 1 patient. The patients age was from 46-82 years old, there were 24 female patients and 36 male patients, 24 diabetic patients, 36 nondiabetic patients, in all cases we did not apply epidural anesthesia.

Anesthesia was used with low doses of fentanyl. in combination with propofol, sevoflurane. In all cases neostigmine was used for decurarisation.

The quality and depth of anesthesia was assessed with obvious signs such as tachycardia, hypertension, sweating. Endogenous stress was also assessed by monitoring glycemia during the intervention.

As extubation criteria were assessed the patient's consciousness, respiratory mechanics, hemodynamic stability, diuresis, bleeding from drains.

Results: 16 patients were extubated in the OR and 44 patients were extubated 15-20 minutes after the intervention in ICU. There was no reintubation. 2 patients were transferred immediately from OR to the repart. 35 patients were transferred to the ward 3-4 hours after extubation. 23 patients were transferred to the ward the next morning. Patients left the hospital after 5-7 days.

Conclusions: Extubation in the OR in the early postoperative period has now become a routine in all specialized clinics. The time spent in the ICU is very low and the day spent in the ward was 5-7 days. The benefit is in the best and fastest activation of patients in the early postoperative period as well as in reduced intervention costs.

Keywords: OR extubation, Early extubation, Cardiac surgery, Benefits

Abbreviations: Operating Room - OR; Cardiopulmonary Bypass - CPB; Coronary Artery Bypass Graft - CABG; Intensive Care Unit - ICU. The Society of Thoracic Surgeons - STS; Adult Cardiac Surgery Database - ACSD; Aortic Valve Replacement - AVR: Hematocrit - Hct; Calafiore - intermittent warm BCP; Crystalloid Cardioplegia - CCP; Blood Cardioplegia - BCP; Mitral Valve Replacement - MVR.
\end{abstract}

Original article, no submission or publication in advance or in parallel

* Corresponding author: Saimir KUÇI MD, Ph.D.

$\bowtie$ saimirkuci@gmail.com

1 Department of Anaesthesiology and Reanimation, German Hospital Tirana, ALBANIA.

2 Department of Cardiosurgery, German Hospital Tirana, ALBANIA

\section{Introduction}

Early extubation of Coronary Artery Bypass Graft (CABG) patients has been shown to reduce costs as well as intensive care unit and hospital lengths of stay [1.2]. It has been a focus of several studies to improve outcomes in the care of CABG patients. According to an analysis from the Society of Thoracic Surgeons Adult Cardiac Surgery Database (STS ACSD) there is a significant variation in post-operative ventilation times in CABG patients providing an opportunity for quality improvement across many institutions [3]. Most studies have focused on CABG patients and few include the impact of early extubation protocols on patients undergoing valve or combined valve and CABG procedures. Prolonged ventilation, defined in the STS ACSD as intubation longer 
than $24 \mathrm{~h}$, is now one of five morbidity measures utilized in composite scores for evaluating performance of isolated CABG, isolated aortic valve replacement (AVR), AVR plus $\mathrm{CABG}$, and mitral or mitral plus CABG procedures [4.5]. In this report we outline our early extubation protocol and have found that it can be effectively adopted for patients having valve and combined CABG and valve procedures as well as isolated $\mathrm{CABG}$ procedures.

\section{Methods and Results}

We applied the early extubation of patients undergoing cardiac surgery at German Hospital Tirana and the postoperative results were satisfactory.

We operated 60 patients from January 2019 to September 2020, who had undergone CABG cardiac operations 52 patients, mitral valve repair 5 patients, aortic stenosis 1patient, Bentall procedure 1 patient, left atrial myxoma 1 patient.

The patients age was from 46 - 82 years old, there were 24 female patients and 36 male patients, 24 diabetic patients, 36 non-diabetic patients, in all cases we did not apply epidural anesthesia. All patient data are summarized in the table below.

We used anesthesia with low doses of fentanyl 5-6 $\mathrm{mcg} / \mathrm{kg} /$ total fractionated in induction of anesthesia, sternotomy and at the time of insertion into the pump. $2.5 \mathrm{mg}$ Midazolam, 120-180 mg Propofol and $8 \mathrm{mg}$ Pancuronium were used to induce anesthesia.

Maintenance anesthesia was done with Propofol 0.5 $\mathrm{mg} / \mathrm{min}$ in combination with sevoflurane.

The quality and depth of anesthesia was assessed with obvious signs such as tachycardia, hypertension, sweating. All patients who underwent surgery did not have tachycardia, hypertension and sweating during the anesthesia. During intervention was performed hypnosis, analgesia and satisfactory relaxation. Endogenous stress was also assessed by measuring glycemia during the intervention. Glycemic values in non-diabetic patients ranged from 90-115 mg / dl, while glycemic values in diabetic patients ranged from 150$170 \mathrm{mg} / \mathrm{dl}$.
Calafiore blood cardioplegia was used in all patients in normothermia in most cases. In 3 patients was used moderate hypothermia $34-35^{\circ} \mathrm{C}$ throughout the intervention. We took care in the administration of the amount of fluid intake, $1500 \mathrm{ml}$ in prime and $500 \mathrm{ml}$ during the intervention used by the surgeon.

During CBP the value of hematocrit (Hct) was kept above $25 \%$ and good perfusion flows of $2.41 / \mathrm{min} / \mathrm{m} 2$ were maintained.

Urine flow during the intervention was maintained above $200 \mathrm{ml} / \mathrm{h}$ using $10 \mathrm{mg}$ Lasix in most cases.

In some cases, positive inotropes (adrenaline, dopamine, dobutamine, noradrenaline) were used for CBP cleavage in minimal doses, mainly in patients with $\mathrm{EF}$ $<40 \%$.

As extubation criteria were assessed the patient's consciousness, respiratory mechanics, hemodynamic stability, diuresis, bleeding from drains. In all cases neostigmine was used for decurarisation, $10 \mathrm{mg}$ Morphine and $1000 \mathrm{mg}$ Analgin with electrical syringe were used for antidolorific therapy. In some cases, paracetamol $1000 \mathrm{mg}$ iv and non-steroidal anti-inflammatory drugs were used.

16 patients were extubated in the OR and 44 patients were extubated 15-20 minutes after the intervention in ICU. There was no reintubation. 2 patients were transferred immediately from $\mathrm{OR}$ to the repart. 35 patients were transferred to the ward 3-4 hours after extubation. 23 patients were transferred to the ward the next morning. Patients left the hospital after 5-7 days.

\section{Discussion}

Early extubation following cardiac surgery is not a novel concept. It was described as early as 1974 by Midell and colleagues in 100 consecutive patients undergoing AVR, MVR, and combined AVR and MVR. Ninety of their patients were able to be extubated in the operating room or within two hours of arrival in the ICU, challenging the standard practice of the time. Morphine was avoided during induction or during the procedure and was used sparingly in the postoperative period. Patients were awakened at the end

\begin{tabular}{|c|c|c|c|c|c|c|c|c|c|c|c|c|c|c|c|c|c|c|}
\hline 60 Patients & 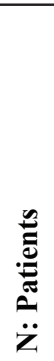 & 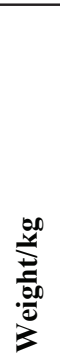 & 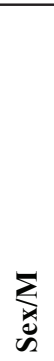 & 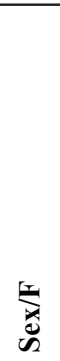 & $\stackrel{80}{Z}$ & 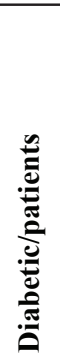 & 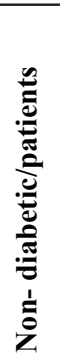 & 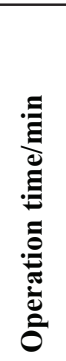 & 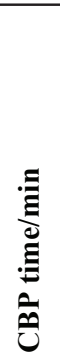 & 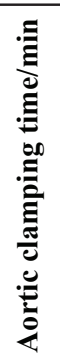 & 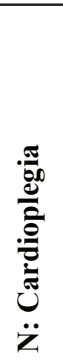 & 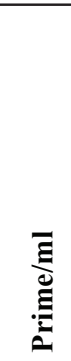 & 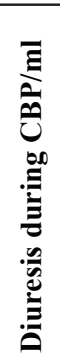 & 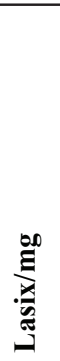 & 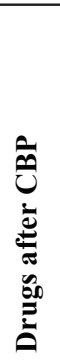 & 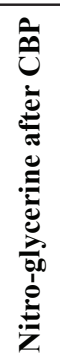 & 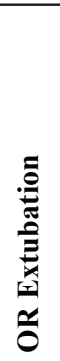 & 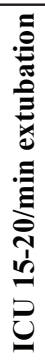 \\
\hline CABG & 52 & 83 & 31 & 21 & 58 & 23 & 29 & 125 & 52 & 33 & 1.2 & 1500 & 500 & 10 & 15 & 48 & 11 & 41 \\
\hline Aortic stenosis & 1 & 75 & 1 & $\mathbf{0}$ & 82 & $\mathbf{0}$ & 1 & 122 & 42 & 29 & 1 & 1200 & 300 & $\mathbf{0}$ & $\mathbf{0}$ & 1 & 1 & $\mathbf{0}$ \\
\hline Bentall operation & 1 & 78 & 1 & 0 & 48 & $\mathbf{0}$ & 1 & 140 & 80 & 70 & 2 & 1500 & 400 & 10 & $\mathbf{0}$ & 1 & 1 & $\mathbf{0}$ \\
\hline Mitral valve repair & 5 & 80 & 3 & 2 & 52 & 1 & 4 & 117 & 45 & 32 & 1.2 & 1500 & 300 & $\mathbf{0}$ & 1 & 3 & 2 & 3 \\
\hline Left atrial myxoma & 1 & 72 & 0 & 1 & 53 & 0 & 1 & 102 & 35 & 26 & 1 & 1500 & 200 & 0 & $\mathbf{0}$ & 0 & 1 & 0 \\
\hline
\end{tabular}


of the procedure, given what today would be considered a "spontaneous breathing trial", and extubated with satisfactory clinical assessment and arterial blood gases. In the early days of cardiac surgery, the routine use of mechanical ventilation was considered a mainstay in the treatment of respiratory failure following extracorporeal circulation. As many of the causes of post perfusion respiratory failure were eliminated, the need for prolonged ventilator support also decreased. Yet it was still standard practice to sedate and ventilate cardiac surgical patients overnight to minimize myocardial oxygen demand and resulting ischemia [6]. In 1977, Prakash and colleagues demonstrated that 123 of 142 adult cardiac surgical patients were able to be extubated in the operating room or within three $h$ of admission to the recovery room [7]. This included patients who had isolated valve replacements and coronary artery bypass procedures. Only five of the 123 patients were re-intubated. They also utilized a spontaneous breathing trial and established criteria for continued mechanical ventilation. If adequate ventilation was maintained with a stable end title $\mathrm{CO}_{2}$ of less than $5.5 \%$ and other hemodynamic criteria were met their patients were extubated. The most common indication for continued mechanical ventilation was low mixed venous oxygen saturation and an elevated left atrial pressure of greater than 20 torr. A controlled randomized trial comparing early extubation within $2 \mathrm{~h}-4 \mathrm{~h}$ to late extubation $18 \mathrm{~h}-21 \mathrm{~h}$ following coronary arterybypasssurgerywaspublishedintheAnesthesialiterature in 1980 [8]. This study demonstrated significantly less cardiopulmonary morbidity in patients who were extubated early. Supporting early extubation of patients following coronary artery bypass surgery was the well described evidence of the pulmonary and cardiac physiologic benefits on hemodynamic, and ventricular performance [9.10]. Another prospective, randomized, controlled trial by Cheng et al." evaluated the outcomes and safety of early extubation after coronary artery bypass grafting [2]. Modifying fentanyl dosing during surgery enabled them to safely extubate $85 \%$ of their patients assigned to the early extubation group. They demonstrated an improvement in postextubation intrapulmonary shunt fraction and a reduction in ICU and hospital length of stay in these patients. Weaning the cardiac surgeon and the care team from the obligatory overnight use of mechanical ventilation has taken more time. The STS ACSD was utilized to study 274,231 patients who underwent elective isolated CABG from 1,008 centers to assess postoperative ventilation time in 2009 and 2010 [3]. In this multi-institutional study of uncomplicated patients who were ventilated for less than $24 \mathrm{~h}$, there was substantial variation in ventilator time across centers. Ventilation times were 1.8 times higher in centers above the 90th percentile compared to those below the 10th percentile and that difference was not accounted for by patient characteristics after adjusting for case mix. This study was published in 2013 and was a clarion call for a quality improvement initiative to strive for the shortest possible ventilation times for all patients. The institution of an effective rapid wean program for cardiac surgical patients is a multi-disciplinary team effort that includes cardiac surgeons, anaesthesiologists, physician assistants, intensive care unit (ICU) nurses, and respiratory therapists. When we evaluated our traditional weaning process, we recognized that one of the impediments to rapid weaning was the need for an individual order for each step of the process. We eliminated that by establishing a protocol with a single order set to initiate the Cardiothoracic Care Unit Rapid Wean Protocol on arrival from the operating room. We also recognized the importance of consistent application of objective criteria for determining the readiness to wean and extubate as outlined in Appendix 1. A Cochrane review and meta-analysis of weaning protocols in critically ill patients has concluded that weaning protocols decrease total duration of ventilation, weaning duration, and length of stay in the intensive care unit [11]. However, these weaning protocols were not specific for cardiac surgery. A standardized protocol for decreasing postoperative mechanical ventilation for cardiac surgical patients is the framework that drives the process. These criteria provide a framework for our care team to proceed independently and proactively with weaning and extubation. The intensive care nurses as well as the respiratory therapists become the drivers of the process [12]. We recognize a major weakness of this manuscript lies in its retrospective and non-randomized design. In addition, we did not attempt propensity matching of the patients. Our goal was to implement a rapid wean protocol for all of our cardiac surgical patients and measure how well we achieved that process as a quality improvement initiative. We did not measure outcome variables in our assessment of this process improvement project but plan to do so. Other studies have demonstrated improved clinical outcomes as well as improved utilization of health care resources can result from early extubation of cardiac surgical patients [1.2]. We embarked on this quality improvement initiative and have demonstrated that a rapid wean protocol can be safely implemented for patients undergoing coronary artery bypass surgery, isolated valve surgery, and combined CABG and AVR procedures. It requires a multidisciplinary team effort with modification of the anesthetic management, adjustments in postoperative pain management, and protocol driven weaning parameters. Most importantly it requires a team effort to insure effective implementation.

\section{Conclusions:}

Extubation of patients in the operating room and in the early postoperative period has now become routine in all specialized clinics. The time spent in the ICU is very low and the length of stay in the ward is 5-7 days. The benefit is the avoidance of complications that occur from postoperative respiratory assistance, better and faster activation of patients in the early postoperative period as well as in the reduced costs of the intervention. 
COI Statement: This paper has not been submitted in parallel. It has not been presented fully or partially at a meeting or podium or congress. It has not been published nor submitted for consideration beforehand.

This research received no specific grant from any funding agency in the public, commercial, or non-profit sectors. There are no relevant or minor financial relationships from authors, their relatives or next of kin with external companies.

Disclosure: The authors declared no conflict of interest. No funding was received for this study.

Acknowledgement: We would like to thank medical staff of Department of Anaesthesiology and Reanimation, German Hospital Tirana, ALBANIA.

\section{References}

1. Arom KV, Emery RW, Petersen RJ, Schwartz M. Costeffectiveness and predictors of early extubation. Ann Thorac Surg. 1995;60(1):127-32.

2. Cheng DC, Karski J, Peiston C, Asokkumar B, Raveendra $\mathrm{G}$, Carroll J, et al. Morbidity outcome in early versus conventional tracheal extubation after coronary artery bypass grafting: A prospective randomized controlled trial. J Thorac Cardiovasc Surg. 1996; 112(3):755-64.

3. Jacobs JP, He X, O'Brien S, Welke KF, Filardo G, Han $\mathrm{JM}$, et al. Variation in ventilation time after coronary artery Bypass grafting: an analysis from the Society of Thoracic Surgeons adult cardiac surgery database. Ann Thoracic Surg. 2013;96(3):757-62.

4. Shahian DM, He X, Jacobs JP, Kurlansky PA, Badhwar V, Cleveland JC Jr, et al. The Society of Thoracic Surgeons composite measure of individual surgeon performance for adult cardiac surgery: a report of the society of thoracic surgeons quality measurement task force. Ann Thorac Surg. 2015;100(4):1315-25.

5. Badhwar V, Rankin JS, He X, Jacobs JP, Gammie JS, Furnary AP, et al. The Society of Thoracic Surgeons mitral repair/replacement composite score: a report of the STS Quality Measurement Task Force. Ann Thorac Surg. 2016;101(6):2265-71.

6. Lefemine AA, Harken DE. Postoperative care following open heart operations: routine use of controlled ventilation. Thorac Cardiovasc Surg. 1966;52(2):207-16.

7. Prakash O, Jonson B, Meij S, Hugenholtz PG, Nauta J, Hekman W. Criteria for Early extubation after intracardiac surgery in adults. Anesth Analg. 1977;56(5):703-8.

8. Quasha AL, Loeber N, Feeley TW, Ullyot DJ, Roizen MF. Postoperative respiratory care: A controlled trial of early and late extubation following coronary artery bypass grafting. Anesthesiology. 1980;52(28):135-41.

9. Butler J, Chong GL, Pillai R, Westaby S, Rocker GM. Early extubation after coronary artery bypass surgery: effects on oxygen flux and hemodynamic variables. J Cardiovasc Surg. 1992; 33: 276-80.

10. Gall SA, Olsen CO, Reves JG, McIntyre RW, Tyson GS Jr, Davis JW, et al. Beneficial effects of endotracheal extubation on ventricular performance. J Thorac Cardiovasc Surg. 1988;95(5):819-27.

11. Blackwood B, Alderdice F, Burns K, Cardwell C, Lavery G, O'Halloran P. Use of weaning protocols for reducing duration of mechanical ventilation in critically ill adult patients: Cochrane systemic review and meta-analysis. BMJ. 2011;342:c7237.

12. Fitch ZW, Debesa O, Whitman GJR, et al. A protocol-driven approach to early extubation after heart surgery. J horac Cardiovasc Surg. 2014;147(4):1344-50. 